\title{
Critical realist approaches to global learning: A focus on education for sustainability
}

\author{
Dima Khazem* - UCL Institute of Education, UK
}

\begin{abstract}
Critical realism offers a useful epistemology and ontology for conceptualizing theoretical and methodological considerations in global learning and may help to bridge the quantitative/qualitative divide that plagues social science. This article elaborates critical realist principles, concepts and methodologies to explain how they can be employed within global learning, with examples from education for sustainability.
\end{abstract}

Keywords: ontological realism; epistemological relativism; judgemental rationality; education for sustainability; climate change

\section{Introduction}

At the 'Research, evidence and policy learning for global education' conference held in May 2017 in London, Professor Annette Scheunpflug, 'a key figure in Europe in promoting the concept of global learning' (Bourn, 2015: 72), spoke about the dilemmas of showing evidence and efficacy in recent educational policy discourse, and how the qualitative/quantitative divide that plagues social science affects research into global learning. As a member of the conference audience at the time, I suggested that critical realism, a meta-theory that I employ in my research, may offer a way forward for theoretical and methodological innovation within the field of global learning. Furthermore, critical realism, with its claim of methodological specificity, may help to mitigate the quantitative/qualitative dualism and bolster research evidence in global learning for policy consideration. This article proposes critical realist approaches to global learning and examines relevant theoretical and methodological issues with a specific focus on education for sustainability.

Critical realism is the brainchild of philosopher Roy Bhaskar, who was World Scholar at the UCL Institute of Education, London, until his death in 2014. It has its roots in long-standing debates about reality and our ability to understand the world in the Western tradition - for example, Plato's allegory of the cave and how Plato believed we come to know things and Kant's distinction between phenomena and noumena, which elaborates the difference between things in themselves as opposed to how they appear to the observer.

In his seminal work A Realist Theory of Science, Bhaskar (1975) began developing this meta-theory - that is, a theory concerned with the investigation, discussion and structure of other theories and with critically exploring their frameworks - and he made clear distinctions between critical realism and other meta-theories, such as positivism and hermeneutics. Critical realism is characterized by three principles: 
- Ontological realism: being is real and the world exists and acts independently of our knowledge of it (Bhaskar, 1975).

- Epistemological relativism: knowledge is socially produced under specific social and linguistic conditions and is therefore changeable and fallible (Bhaskar, 1975, 1998).

- Judgemental rationality: it is possible to arrive at decisions between relative and competing beliefs or theories because not all interpretations are epistemically or morally equal and there can be rational grounds for preferring one to another (Bhaskar, 2016).

These three principles will be discussed and applied as an approach to global learning with specific examples from education for sustainability. Before doing so, it is worth reminding ourselves that global learning seeks to empower people to engage with the complex global systems in which we live and their implications for their lives and the sustainability of the earth (Whitehead, 2015). Furthermore, global learning is a guiding principle defined by issues such as development, environment, peace and interculturalism; and by competencies that should be acquired to live in globalized societies (Bourn, 2014). As such, global learning covers 'adjectival educations' such as environmental education, which was redefined in the 1990s as education for sustainable development and/or education for sustainability (Bourn, 2015).

It can be argued that there is a case for reorienting education as a whole as sustainability and not for sustainability (Foster, 2001), but for the purpose of this article the term 'education for sustainability' is used. In terms of theoretical frameworks, Bourn (2015) suggests that global learning is influenced by Scheunpflug's (2008) work based on Kantian notions of ethical reasoning and freedom and Andreotti's (2010) work, which adopts a Freirean critical stance and a post-colonialist lens. So, what principles and concepts can critical realism offer as an alternative approach to global learning? And how can it help mitigate the qualitative/quantitative divide? To start with, let us maintain that the world is real.

\section{Ontological realism}

Critical realism proposes that the world is real, structured and complex and in its earlier beginnings as transcendental realism (Bhaskar, 1975), is a philosophy of science that is very useful when examining debates about sustainability and climate change, both within and outside of schools. Furthermore, it argues for ontology, or being, which is real and independent of epistemology, or knowledge and contends that our reality consists of the domains of the real, the actual and the empirical, where the real (structures and mechanisms) generates the actual (events) and is distinct from the empirical (experiences of humans) (Bhaskar, 1975). As such, Bhaskar's 'argument suggests a critique of the epistemic fallacy, that is, the reduction of being to knowledge, or the reduction of ontological to epistemological questions' (Bhaskar et al., 2018: 28). To counter the epistemic fallacy, Bhaskar proposes two dimensions of knowledge, the transitive and intransitive dimensions. The transitive dimension is the aspect of knowledge that involves people and their beliefs and theories and is thus socially produced, while the intransitive dimension is the world that exists independently of people's beliefs.

By arguing for ontology and against the epistemic fallacy, which considers being as knowledge about being, critical realism helps us place the natural world in reality, independent of human thought and therefore protects against the anthropic fallacy, which is the 'exegesis of being in terms of human being' (Bhaskar, 1993: 205). 
In other words, nature and the environment thus exist in the intransitive domain of the real and are not a transitive, empirical construction; therefore, they have value in themselves, independent of our human thoughts and beliefs about the natural world. This argument is strongly supportive of the environmental concerns that are expressed within education for sustainability and sits happily within the realm of global learning. By insisting that nature is real, critical realism lends strength to the argument against the endless expansion of human activity and supports sustainability and the protection of the natural environment and, indeed, people and the planet. Thus, ontological realism is very helpful for global learning, because if the environment is not ontologically real, and is constructed rather than construed, then what are we trying to sustain and what is the point of education for sustainability?

Moreover, critical realism does not only argue for ontology, but for a new, interconnected and structured ontology. First, it rejects the Humean classical-empiricist premise that events happen as a constant conjunction in a closed system regulated by experimental conditions such as those artificially isolated in a laboratory, maintaining, rather, that reality is an open system where mechanisms and structures operate and interconnect without the constant conjunctions of the experimental context (Bhaskar, 1975). This is very useful for considering the complex and interconnected issues and debates surrounding sustainability, as well as global phenomena such as climate change, which happens in the biosphere, a widely open and complex system. Second, critical realism maintains that reality is both laminated, that is, made of different layers and differentiated, that is, consisting of internal elements bonded in a multiplicity of structures and interrelations to form more complex, or higher order, beings or things. This complexity applies both to social and to material life:

where the state of the higher-order level provides the causally efficacious conditions for the state of the lower order level ... this is the kind of effect that human beings are having on the environment, such as global warming, and it is a necessary condition for any intentional action. (Bhaskar et al., 2018: 31)

By maintaining that reality is structured and emergent, critical realism helps us to consider the different and interconnected spheres of activity that contribute to sustainability, including those that contribute to, or engender, mitigation of climate change. By maintaining that the world is complex and interconnected, critical realism lends valuable support to theoreticians and practitioners of global learning. Specifically, Shah and Brown (2010) emphasize the importance of situating learning in a global context, the need to respond to change and complexity, and the adoption of various perspectives. Furthermore, Bourn (2015: 45) cites Shah and Brown (2010) in maintaining that critical thinking for global learning needs to include 'making connections within and between systems particularly in terms of social and environmental dimensions'. Scheunpflug (2011) also contends that global learning is defined by competencies that include the ability to understand and critically reflect global interdependencies.

Furthermore, critical realism, in its recognition of ontological complexity and the totality of real-world phenomena, has embraced interdisciplinarity as an approach (Bhaskar and Danermark, 2006; Bhaskar, 2010; Bhaskar et al., 2018). This is because the nature of causal determination operating in an open system implies a multiplicity of causes and supports holistic causality, rather than atomistic causality based on constant conjunctions of events. As Porpora (2015: 46) suggests, 'critical realism does not conceive causality in terms of regularities nor even in terms of events ... [but] as a relation between causal structures or mechanisms and causal properties ... in the open 
world where multiple mechanisms always operate'. This multiplicity of causal structures and mechanisms implies in turn a multiplicity of theories and disciplines needed to explain real phenomena and is also useful for social research. Applied to education for sustainability, this is very useful when dealing with the intertwining ecological, physical, political, social, economic, cultural and psychological dimensions of sustainability and climate change (Cornell, 2010; Cornell and Parker, 2010; Næss, 2010; Parker, 2010). It also has theoretical, policy and practical implications when considering where and how education for sustainability can be dealt with within education and posits the need for a more interdisciplinary approach in curriculum development. In terms of global learning itself, Bourn (2015: 9) maintains that 'learning about other places or the world in general cannot however be divorced from social, cultural, economic and political motivations and lenses'. This would call for an interdisciplinary approach that can help bring the adjectival educations within global learning together, including education for sustainability, peace, human rights and global citizenship. For example, within education for sustainability, climate change can easily be linked to education about human rights, global citizenship and peace, because of its complex impacts. Climate change is not simply a phenomenon occurring in the environment and although it is largely attributed to human activity, it can 'interfere with the realization of fundamental, internationally recognized human rights - including those protected by the International Covenant on Economic, Social, and Cultural Rights and the International Covenant on Civil and Political Rights' (CIEL, 2011: 1). Alongside rights protected in these two 1966 covenants, the threat to human rights was recognized by the United Nations Human Rights Council (UNHRC) (2008, 2009), which adopted two consensus resolutions in March 2008 (Resolution 7/23) and March 2009 (Resolution 10/4) to that effect, with the latter resolution noting that:

climate change-related impacts have a range of implications, both direct and indirect, for the effective enjoyment of human rights including, inter alia, the right to life, the right to adequate food, the right to the highest attainable standard of health, the right to adequate housing, the right to self-determination and human rights, obligations related to access to safe drinking water and sanitation, and recalling that in no case may a people be deprived of its own means of subsistence. (UNHRC, 2009: 1)

Moreover, climate change does not only affect human rights pertaining to people's ontology or being, such as those mentioned above related to the preservation and maintenance of life; it can also have an impact on other rights, such as the right to education and culture. Furthermore, Resolution 10/4 states that the impacts of climate change 'will be felt most acutely by those segments of the population that are already vulnerable owing to geography, gender, age, indigenous or minority status and disability' (UNHRC, 2009). By affecting vulnerable people most, climate change can worsen the living conditions and human rights of people who may already suffer from human rights violations and so further contribute to social injustice and inequality and engender social ills and conflicts.

Critical realism maintains that 'there is no reason why states of affairs such as health, de-alienation, education, access to information, etc. should not be seen as rights and so as freedoms' (Bhaskar, 1993: 259). However, achieving the goal of human rights 'depends upon the transformation of structures rather than the amelioration of states of affairs' (Bhaskar, 1986: 171). Evidently, this approach has clear benefits for global learning that encourages people to transform their lives and exercise their agency for social change. A critical realist approach to global learning, including education for 
sustainability, can play a role in raising awareness of and protecting people's rights. Furthermore, critical realism, with its emphasis on interdisciplinarity, helps us deal with the interconnectedness and complexity of the world we live in, and can be insightful as a theoretical lens for global learning. Bhaskar's model, which he calls the seven laminations of scale, where higher orders of reality emerge from lower-order ones, can serve as a guide to interdisciplinarity (Lotz-Sisitka and Price, 2016; Price, 2014; Bhaskar, 2010; Bhaskar et al., 2018). This seven-scalar model ranges from the planetary level to the sub-individual or psychological level and alerts us to a more complex understanding of emergent issues such as sustainability and climate change. This model, encompassing seven layers or laminations of reality, has excellent applications when applied to global learning and helps us consider how our activities can engender and promote active citizenship, social change and sustainability, including mitigating or exacerbating climate change. At the same time, another useful critical realist principle that has helpful methodological implications is epistemological relativism.

\section{Epistemological relativism}

Critical realism contends that knowledge is socially produced, changeable and fallible and that science is an ongoing social activity in a continuing process of transformation (Bhaskar, 1975). This is useful when considering debates about sustainability and the uncertainties and denials about climate change and how they should be dealt with within education. Epistemological relativism also means that our knowledge of the world 'is of (or about) things and structures that are existentially independent of us, and relatively or absolutely independent causally' (Bhaskar, 2016: 26). Furthermore, because knowledge is socially produced, this means that the world is known, interpreted and experienced differently by different people. This last feature is very similar to hermeneutic, post-structural and other idealist stances that influence research into global learning and has implications for methodology. However, critical realism offers an additional value compared to relativism because it insists on separating being (ontology) from knowledge about being (epistemology). This has implications for methodology because, while taking context into account, critical realism allows us to make conclusions in a more certain way than that offered by relativism because we are able to detach the ontological conclusion of an epistemic investigation from the investigation itself (Bhaskar, 2016). Furthermore, while rejecting Humean atomistic causality, as in positivism, critical realism argues for holistic causality through the totality of connections and interrelations arising from real, generative mechanisms, which allows for more certainty than that offered by relativism.

As such, critical realism claims that it is profitable to combine methods in social research and that the qualitative versus quantitative 'discussion and polarization is not only fruitless, but ... is also misleading' (Danermark et al., 2002: 151). However, it does not argue for a critical methodological pluralism where 'anything goes' (Feyerabend, 1975). Instead, it argues for methodological specificity in which 'all methods are not equally suitable' and their suitability is determined by the nature of the research object itself (Danermark et al., 2002: 152). In trying to go beyond the qualitative and quantitative research method dichotomy, it introduces the concept of intensive and extensive design, where mixed methods are useful in explaining generative mechanisms, as well as in explaining how mechanisms manifest themselves in various contexts (Danermark et al., 2002). Thus, intensive methods involve a substantial element of data collection and analysis of a qualitative kind and extensive methods employ quantitative data collection and statistical analysis. However, this is not simply a pragmatic approach to 
mixed methods research but one that hopes to engender an explanatory critique by determining the holistic generative mechanisms behind the data and favours the use of abduction and retroduction - logical inferences that start with a set of observations and seek to find the most simple or likely explanation for them - rather than induction or deduction, which are associated with hermeneutics and positivism respectively (Danermark et al., 2002). Pawson and Tilley (1997: 57), whose work on crime prevention and evaluation was informed by critical realism, although it is distinct from it, summarize the critical realist model of social investigation as follows: 'generative mechanisms + context = outcomes'. Holland (2014: 201) praises this model because 'it has much to recommend it, not least its emphasis on the contingency of social causation'.

As such, by providing an alternative to positivism and hermeneutics and their associated methodological dichotomies, critical realism may help breach the qualitative/quantitative divide so often encountered in social research and can provide a way forward for innovative methodological practices in global learning. As Porpora (2015: 63) suggests, critical realism does not pose an opposition between qualitative and quantitative methods, unlike positivism and interpretivism. Instead, critical realism 'reunifies sociological methodology'. By embracing single, multi-method and mixed method research, depending on what suits where and when to address the research object, critical realism may help address concerns about evidence-based research encountered by researchers in global learning when addressing the demands of funders and policymakers. Some detailed methodological and conceptual discussions and examples of critical realist investigations in education for sustainability are elaborated by Leigh Price and Heila Lotz-Sisitka, among others, in their 2016 book, Critical Realism, Environmental Learning and Social-Ecological Change.

\section{Judgemental rationality}

Combined with epistemological relativism, discussed above, the critical realist principle of judgemental rationality allows us to maintain that despite the fact that knowledge is fallible - that is, capable of being wrong - and is socially and linguistically mediated, we can still have rational grounds to prefer and support one belief or theory over other competing beliefs and theories (Bhaskar, 2016). As such, critical realism can sustain 'the realist intuitions of post-positivistic modernism without succumbing to their foundationalism; while acknowledging, along with post-modernist constructivism, the social relativity of all our beliefs without resorting to their judgemental irrationalism' (Bhaskar, 2016: 26). Furthermore, judgemental rationality refers to our ability to adjudicate among rival reality constructions, which implies that our various constructions of reality are not equally warranted, but, rather, that some are epistemically superior to others (Porpora, 2015). This is because unlike social constructionism and positivism, which both share an epistemic conception of truth dependent on methodology, critical realism has an alethic view that detaches truth from methodology and the epistemic account (Porpora, 2015). For critical realism, the alethic account of truth is ontological and based on the world itself. Hence, we are able to approximate the truth through holistic causality and alethic account, rather than believing in its absolute certainty as positivism does, or rejecting outright the possibility of truth, as constructionists do. Applied to social research and methodological considerations in combination with the other two pillars of ontological realism and epistemological relativism, this principle of judgemental rationality allows for more certainty about evidence produced for policy and a critical realist approach can help bolster the impact of research in global learning, including that within education for sustainability. 
Another useful application of this principle for global learning is its potential for use within education for peace and interculturalism because Bhaskar (2010) maintains that when applied to conflict resolution, judgemental rationality means that it is possible for human beings to arrive at decisions between relative beliefs and therefore resolve conflict. Resolving our conflicts with other people can be achieved by grounding judgemental rationality upon two capacities (Bhaskar, 2010: 18):

(1) universal solidarity: the capacity to identify with others

(2) axial rationality: the capacity to reconcile with others.

This is a powerful and useful concept because it allows us, as researchers and human beings, to exercise our rational judgements and make statements about reality, while allowing for empathy and reconciliation with others. With reference to education for sustainability, judgemental rationality has an important role to play within the sea of talk about what counts as scientific truth, for example when it comes to climate change, its causes and its mitigation.

In addition to the three principles already discussed, critical realism offers another added value, that of the possibility of change and transformation that is intrinsic to global learning.

\section{Agency and transformation}

Critical realism has argued for the resolution of dichotomies in the social sciences by tackling the dualism of structure and agency, doing justice to both and giving a distinctive role to each without conflating them. Unlike Durkheim, who emphasized structure, and Weber, who stressed agency, the transformational model of social activity (Bhaskar, 1998) maintains that social structures are transcendentally necessary and temporally a priori to human agency, which has a role to play by either reproducing or transforming structures. The connection between structure and agency is the intentionality of human agency, where reasons for action become causes for it. Therefore, as agents, we can either reproduce pre-existing structures or transform them based on our actions. In terms of global learning, this is important because education can be used to secure a degree of personal and social transformation (Bourn, 2015). As such, practitioners and researchers within the field of global learning have a role to play in contributing to our emancipation from social and environmental ills, especially when employing critical realism. This is because for critical realists, any description of the world is both explanatory within a specific set of conceptual relations and potentially transformative of these same relations. In other words, educational processes happen in the open system (Lotz-Sisitka and Price, 2016). The resulting transformed praxis should help students and pupils acquire knowledge, skills and attitudes to help them become active global citizens who are able to act on global concerns. Within education for sustainability, this is very useful for considering the transformative capability of human agency in terms of individual and collective action for sustainability and against climate change. Furthermore, it helps people to consider the real constraining social structures and how they can be transformed so environmental sustainability can be achieved.

Bhaskar elaborated this model of social activity later in his work on dialectical critical realism, which deepens the argument for ontology and focuses its concern on the dialectic processes of transformation and change. He argued that social life is not just a matter of agency and structure; it also takes place in nature (Bhaskar, 1993). He employed the useful concept of the four-planar social being or social cube, which maintains that all social transactions take place on four planes of social activity: relations 
with nature, society, others and the self. One immediate advantage of this model is that it 'pinpoints the ecological dimension of social being that social theorists have been prone to ignore' (Bhaskar, 2016: 83) and is very helpful in conceptualizing research in global learning, with obvious immediate uses for social investigations into education for sustainability. This is because many factors that promote or hinder sustainability are linked to the activities of our body in the material world, our interpersonal relationships, our interactions with social and natural structures and our transactions with our inner being. For example, by analysing our agentive agency and actions to combat and mitigate climate change within the four planes of social activity (self, others, society and nature), or our consumer behaviour and the structures that either constrain us or help us to transform our life, we are able to pinpoint social ills and engage in individual and collaborative transformational praxis to lift them.

Archer (1995), a prominent critical realist who has developed Bhaskar's work on agency through her notion of 'morphogenesis', notes that as persons engage in a process of narrative agency to emerge as citizens or actors, they, alongside others, can engender social change and transform structures through collective agency. Dialectic critical realism (Bhaskar, 1993; Norrie, 2010) elaborates agential change in what it calls 'transformative praxis' to absent absences, or ills. The dialectical critical-realist concept of absence is very helpful, not just in terms of 'the absenting of constraints on the absenting of absences, or ills' (Bhaskar, 1993: 396), but also in alerting us to what is absent, denied, omitted or rejected in reality but that remains desirable or needed in order to absent (remove) ills. This has practical applications for research in global learning. For example, in terms of education for sustainability, the concept of absence can help us see what is missing and where, by examining how education systems deal with sustainability and climate change in terms of policies, institutional ethos, teaching, learning and the curriculum.

Finally, critical realism is characterized by an emancipatory approach that includes taking note of the perspective of participants and even promoting social justice (House, 1991). Bhaskar (1993: 259) maintains that his work is normative and elaborates his concern for emancipatory social practice and a radical agency contained in 'sensitised solidarity of ... praxis and the dialectics of de-alienation and emancipation'. For me, this provides an added value in terms of dealing with issues of sustainability and the threat of climate change to people and planet.

\section{Conclusion}

As a meta-theory, critical realism offers many conceptual, epistemological and methodological approaches that are helpful to global learning and that can bolster evidence for policy considerations. With its emphasis on ontological realism, it maintains that nature and the environment are real, rather than socially constructed, which supports the argument for sustainability, education for sustainability and the restriction of human activity, so as to reduce harm to people and our planet from climate change. Critical realism is helpful in its identification of the ecological plane of social activity, which renders it suitable for global learning and education for sustainability. By calling for absenting ills through agential transformative praxis, it offers the possibility for social transformation and change and proposes a seven-scalar model of reality useful for analysing and examining emergent and complex issues, such as climate change. 


\section{Notes on the contributor}

Dima Khazem is an MA tutor at the UCL Institute of Education, London, where she is also undertaking her doctoral research on the health impacts of climate change in the school curriculum, with a focus on Egypt. Her research interests include health education, especially sexual health, education for sustainability and education, conflict and peacebuilding. She is especially interested in interdisciplinary approaches to social research.

\section{References}

Andreotti, V. (2010) 'Global education in the "21st century": Two different perspectives on the "post"- of postmodernism'. International Journal of Development Education and Global Learning, 2 (2), 5-22.

Archer, M.S. (1995) Realist Social Theory: The morphogenetic approach. Cambridge: Cambridge University Press.

Bhaskar, R. (1975) A Realist Theory of Science. Leeds: Leeds Books.

Bhaskar, R. (1986) Scientific Realism and Human Emancipation. London: Verso.

Bhaskar, R. (1993) Dialectic: The pulse of freedom. London: Verso.

Bhaskar, R. (1998) The Possibility of Naturalism: A philosophical critique of the contemporary human sciences. 3rd ed. London: Routledge.

Bhaskar, R. (2010) 'Contexts of interdisciplinarity: Interdisciplinarity and climate change'. In Bhaskar, R., Frank, C., Høyer, K.G., Næss, P. and Parker, J. (eds) Interdisciplinarity and Climate Change: Transforming knowledge and practice for our global future. London: Routledge, 1-24.

Bhaskar, R. (2016) Enlightened Common Sense: The philosophy of critical realism. Ed. Hartwig, M. London: Routledge.

Bhaskar, R. and Danermark, B. (2006) 'Metatheory, interdisciplinarity and disability research: A critical realist perspective'. Scandinavian Journal of Disability Research, 8 (4), 278-97.

Bhaskar, R., Danermark, B. and Price, L. (2018) Interdisciplinarity and Wellbeing: A critical realist general theory of interdisciplinarity. London: Routledge.

Bourn, D. (2014) The Theory and Practice of Global Learning (Development Education Research Centre Research Paper 11). London: Institute of Education.

Bourn, D. (2015) The Theory and Practice of Development Education: A pedagogy for global social justice. London: Routledge.

CIEL (Center for International Environmental Law) (2011) Climate Change and Human Rights: A primer. Washington, DC: Center for International Environmental Law. Online. www.ciel.org/ Publications/CC_HRE_23May11.pdf (accessed 18 August 2018).

Cornell, S. (2010) 'Climate change: Brokering interdisciplinarity across the physical and social sciences'. In Bhaskar, R., Frank, C., Høyer, K.G., Næss, P. and Parker, J. (eds) Interdisciplinarity and Climate Change: Transforming knowledge and practice for our global future. London: Routledge, 116-34.

Cornell, S. and Parker, J. (2010) 'Critical realist interdisciplinarity: A research agenda to support action on global warming'. In Bhaskar, R., Frank, C., Høyer, K.G., Næss, P. and Parker, J. (eds) Interdisciplinarity and Climate Change: Transforming knowledge and practice for our global future. London: Routledge, 25-34.

Danermark, B., Ekstrom, M., Jakobsen, L. and Karlsson, J.C. (2002) Explaining Society: Critical realism in the social sciences. London: Routledge.

Feyerabend, P. (1975) 'How to defend society against science'. Radical Philosophy, 11 (1), 3-9.

Foster, J. (2001) 'Education as sustainability'. Environmental Education Research, 7 (2), 153-65.

Holland, D. (2014) Integrating Knowledge through Interdisciplinary Research: Problems of theory and practice. London: Routledge.

House, E.R. (1991) 'Realism in research'. Educational Researcher, 20 (6), 2-25.

Lotz-Sisitka, H. and Price, L. (2016) 'Why critical realism, environmental learning and socialecological change? Introducing the book'. In Price, L. and Lotz-Sisitka, H. (eds) Critical Realism, Environmental Learning and Social-Ecological Change. London: Routledge, 1-17.

Næss, P. (2010) 'The dangerous climate of disciplinary tunnel vision'. In Bhaskar, R., Frank, C., Høyer, K.G., Næss, P. and Parker, J. (eds) Interdisciplinarity and Climate Change: Transforming knowledge and practice for our global future. London: Routledge, 54-84. 
Norrie, A. (2010) Dialectic and Difference: Dialectical critical realism and the grounds of justice. London: Routledge.

Parker, J. (2010) 'Towards a dialectics of knowledge and care in the global system'. In Bhaskar, R., Frank, C., Høyer, K.G., Næss, P. and Parker, J. (eds) Interdisciplinarity and Climate Change: Transforming knowledge and practice for our global future. London: Routledge, 205-26.

Pawson, R. and Tilley, N. (1997) Realistic Evaluation. London: SAGE Publications.

Porpora, D.V. (2015) Reconstructing Sociology: The critical realist approach. Cambridge: Cambridge University Press.

Price, L. (2014) 'Critical realist versus mainstream interdisciplinarity'. Journal of Critical Realism, 13 (1), 52-76.

Price, L. and Lotz-Sisitka, H. (eds) (2016) Critical Realism, Environmental Learning and SocialEcological Change. London: Routledge.

Scheunpflug, A. (2008) 'Why global learning and global education? An educational approach influenced by the perspectives of Immanuel Kant'. In Bourn, D. (ed.) Development Education: Debates and dialogues. London: Institute of Education, 18-27.

Scheunpflug, A. (2011) 'Global education and cross-cultural learning: A challenge for a researchbased approach to international teacher education'. International Journal of Development Education and Global Learning, 3 (3), 29-44.

Shah, H. and Brown, K. (2010) 'Critical thinking in global learning'. In Wisely, T.L.K, Barr, I.M., Britton, A. and King, B. (eds) Education in a Global Space: Research and practice in initial teacher education. Edinburgh: International Development Education Association of Scotland, 37-42.

UNHRC (United Nations Human Rights Council) (2008) 'Resolution 7/23: Human rights and climate change'. Online. http://ap.ohchr.org/documents/E/HRC/resolutions/A_HRC_RES_7_23.pdf (accessed 13 September 2018).

UNHRC (United Nations Human Rights Council) (2009) 'Resolution 10/4: Human rights and climate change'. Online. http://ap.ohchr.org/documents/E/HRC/resolutions/A_HRC_RES_10_4.pdf (accessed 13 September 2018).

Whitehead, D.M. (2015) 'Global learning: Key to making excellence inclusive'. Liberal Education, $101(3), 6-13$. 